\title{
A IMIGRAÇÃO VENEZUELANA COMO PROBLEMA DO SETOR PÚBLICO
}

\section{ARTIGO DE REVISÃO}

OJEDA, Nataly Luiza Nantes ${ }^{1}$

FONSECA, Mirella Villa de Araújo Tucunduva da ${ }^{2}$

OJEDA, Nataly Luiza Nantes. FONSECA, Mirella Villa de Araújo Tucunduva da. A imigração venezuelana como problema do Setor Público. Revista Científica Multidisciplinar Núcleo do Conhecimento. Ano 05, Ed. 10, Vol. 16, pp. 103-115. Outubro de 2020. ISSN: 2448-0959, Link de acesso: https://www.nucleodoconhecimento.com.br/administracao/imigracaovenezuelana

\section{RESUMO}

A Venezuela vive desde 2013 uma crise política, humanitária e econômica, como reflexo dessa crise houve uma grande saída de venezuelanos que fugiam dos confrontos e da falta de insumos básicos para sobrevivência. Muitos desses migrantes optam por regiões próximas ao país de origem para não distanciar muito da família. Roraima é o mais afetado dos estados brasileiros, visto que é fronteira com a Venezuela, o grande fluxo migratório acontece pelo município de Pacaraima. O presente artigo explana sobre a migração venezuelana para o Brasil e como ocorre a recepção, interiorização e as politicas públicas adotadas pelo governo brasileiro, suas causas e impactos. A pesquisa foi realizada, metodologicamente, com base em

1 Pós-Graduação Lato Sensu em Gestão Pública (UFMS), Graduação em Direito (UNIDERP).

2 Orientadora. Doutorado em Educação. Mestrado em Educação. Especialização em andamento em Metodologias e Gestão para Educação a Distância. Especialização em Educação Especial. Especialização em Psicopedagogia. Graduação em pedagogia. 
estudo bibliográfico, documental, onde foram analisados livros, revistas, paginas da web e legislação, para a consecução do resultado final do presente artigo científico. Como sugestão para o problema enfrentado cita-se, ao final do deste, a integração e cooperação da tripartite do governo (federal, estadual e municipal) com entidades não governamentais e a sociedade civil através de uma estratégia de incentivos e sensibilização social.

Palavras-chave: Imigração venezuelana, políticas públicas, interiorização.

\section{INTRODUÇÃO}

Desde que Nicolás Maduro assumiu o governo, após a morte do Hugo Chávez, houve um aumento no descontentamento da população com o governo que apresentava inflação de mais de $800 \%$ ao ano, a alta no preço do petróleo elevou exorbitantemente os preços dos produtos, causando a escassez e o racionamento de produtos nos mercados e o aumento no índice de desemprego. Esses foram alguns dos pontos que agravaram a situação na Venezuela, milhares de venezuelanos começaram a migrar para outros países buscando oportunidades de terem uma vida mais digna e fugindo do colapso econômico que resultou na crise humanitária, econômica e social vivida na Venezuela.

A maioria dos migrantes prefere fugir para regiões próximas a fronteira, para ficarem perto de suas famílias e por acreditarem ser mais fácil voltar após a crise, isso gerou grandes transtornos nos países fronteiriços que não estavam preparados para esse aumento no número de migrantes. Roraima é o estado brasileiro mais afetado pela migração venezuelana devido a sua proximidade com a Venezuela, o fluxo migratório vem pelo município de Pacaraima. Ao chegar no Brasil os venezuelanos enfrentam situação de vulnerabilidade e marginalização, pois ficam em praças públicas, ruas ou abrigos improvisados, aumentando números de violência, roubos, estupros e pedintes nas ruas. Para conseguir dinheiro se sujeitam a situações análogas ao trabalho escravo e sofrem várias violações de direitos trabalhistas, além de enfrentar problemas como xenofobia. 
Roraima não consegue abrigar a grande concentração de venezuelanos que migraram em busca de insumos básicos que faltavam em seu país e que vem em busca de ofertas de empregos e novas oportunidades de prosperidade. Tendo em vista a crise humanitária, a vulnerabilidade e a violação dos direitos humanos que acomete os venezuelanos no cenário atual, o governo brasileiro precisou tomar parte e criar e fazer valer politicas públicas para realocação e socialização dos migrantes no país, para isso foi feito um estudo pelo governo federal em parceria com as Forças Armadas, Ministérios da Esplanada, agências do sistema ONU no Brasil e entidades civis, para interiorização, que visa distribuir para outros estados esse contingente proporcionando oportunidades de trabalhos e possibilidades de uma vida digna.

O presente trabalho buscou, mesmo diante da escassez de números oficiais, mostrar como vem ocorrendo o fluxo migratório venezuelano, apontar as principais dificuldades na chegada ao Brasil, analisar o Programa de Interiorização da Operação Acolhida e qual governo vem sendo a conduta do governo para ajudar o combate à discriminação da sociedade brasileira em relação aos imigrantes.

\section{O AUMENTO DO FLUXO MIGRATÓRIO VENEZUELANO PARA O BRASIL}

Nicolás Maduro assumiu o poder em 2013, após a morte de Hugo Chávez, que estava na presidência da Venezuela desde 1999. Com a morte Chávez, o até então vicepresidente, Maduro, assumiu o poder em caráter interino e convocou novas eleições, sendo eleito para um mandato de seis anos no dia 15 de abril de 2013. Embora no início do mandato Maduro tivesse alto índice de aprovação, logo os problemas começaram a aparecer, a economia já estava devastada, razão que levou a queda no preço dos barris de petróleo, produto principal de exportação da Venezuela e origem das receitas que financiavam serviços e programas sociais. As vendas de petróleo representavam $98 \%$ das receitas de exportação e até $50 \%$ do Produto Interno Bruto (PIB). Maduro foi reeleito em maio de 2018, em uma eleição com inúmeras denúncias de fraude e acusação de violação de princípios básicos da democracia. A legitimidade 
da eleição foi contestada pela oposição e pela comunidade internacional, gerando o acirramento na crise venezuelana.

Para se ter uma noção na situação na Venezuela, segundo Rupert Colville, porta-voz do Alto Comissariado para Direitos Humanos da ONU, que entre os dias 21 e 26 de janeiro de 2019 mais de 850 pessoas foram presas pelo país, maior número de detenções em décadas no país, entre os presos, há 77 crianças, algumas delas de apenas 12 anos, a organização também divulgou que o número de mortos nas repressões ocorridas chegou a 40. Isso foi reflexo de uma investida da oposição que autodeclarou presidente interino o opositor Juan Guaidó. (G1, 2019)

Conforme divulgado pela Organização Internacional para as Migrações (OIM) e a Agência da ONU para Refugiados (ACNUR), o número de refugiados venezuelanos disparou de cerca de 695 mil no final de 2015 para mais de 4 milhões até meados de 2019, se tornando dos maiores grupos populacionais deslocados de seu país. Os dados são alarmantes cerca de um milhão de pessoas deixaram a Venezuela desde novembro de 2018. Os países que mais receberam os venezuelanos são a Colômbia por cerca de 1,3 milhão, seguida pelo Peru, com 768 mil, o Chile 288 mil, o Brasil 168 mil e, a Argentina, 130 mil. (ACNUR, 2019)

A principal diferença entre a expressão "imigrante" e "refugiado", é que o imigrante tem a intenção de retornar ao seu país, mesmo que de forma ilusória, já o refugiado dificilmente conseguirá retornar, seja por opção ou por questões alheias a sua vontade. A legislação brasileira reconhece como refugiadas "as pessoas que foram obrigadas a sair de seus países devido à violação generalizada de direitos humanos" (ACNUR, 2010).

Canineu (2017), cita o fato de o governo venezuelano não reconhecer a existência de uma crise humanitária o que impediu que a população se enquadrasse no perfil de refugiados adotado internacionalmente. 
Para Rodrigues (2006), dentre as vertentes das migrações internacionais, nota-se deslocamentos expressivos dentro da América Latina e principalmente, entre os países fronteiriços.

Segundo Simões:

A imigração venezuelana no Brasil cresceu exponencialmente nos últimos anos e sua presença vem ganhando amplo destaque nos dados estatísticos e nos diferentes discursos políticos, acadêmicos e da mídia. Tem sido expressivo o número de venezuelanos chegando via fronteira norte do país, pela cidade de Pacaraima, no estado de Roraima. O número de solicitantes de refúgio venezuelanos passou de 829 , em 2015, para 3.368, em 2016, e 7.600 venezuelanos pediram refúgio no país até junho de 2017. Da mesma forma que os chamados "novos fluxos migratórios" provenientes do sul global e iniciados a partir de 2010, como é o caso dos imigrantes haitianos, senegaleses e bengalis, entre outros, a imigração venezuelana também é caracterizada pela diversificação e possui diferentes origens: geográficas, sociais, culturais, entre outras (SIMÕES et al, 2017, p. 09).

A falta de politicas públicas e integradoras na inserção dos venezuelanos aos sistemas públicos seja na saúde, educação, moradia, empregos e a falta de parceria entre governos federais, estaduais e municipais tornam dramática a situação dos imigrantes no Brasil, muitos acabam em semáforos vendendo alimentos ou pedindo esmolas e em alguns casos até se prostituindo. O governo brasileiro demorou a assumir responsabilidades quanto aos problemas surgidos em Roraima, essa falta de acolhimento e o aumento da violência geraram casos de xenofobia (discriminação ou aversão a pessoas estrangeiras), pois os brasileiros passaram a disputar empregos e serviços públicos com os imigrantes. (SOUSA, 2019)

O Governo Federal visando resolver o problema de superlotação em Roraima criou em 05 de abril de 2018, o Programa de Interiorização dos imigrantes venezuelanos a fim de redistribuir geograficamente e promover melhores oportunidades de sobrevivência e acolhimento de forma segura, digna e adequada. Ações preventivas contra as violações dos diretos trabalhistas, tráfico de pessoas e trabalho escravo também tem sido executadas pelo governo federal em parceria com órgãos especializados. (SAMPAIO, 2018) 


\section{METODOLOGIA}

Utilizando o método de pesquisa qualitativa e pesquisa explicativa procurou-se a compreensão de um grupo social e das organizações, buscando explicar como se ocorre o fluxo migratório da Venezuela para o Brasil e quais seus reflexos nas politicas públicas ou na falta delas, preocupando com aspectos da realidade que não podem ser quantificados, visando compreender e explicar como se dão as relações sociais. O objetivo da amostra é a produção de informações aprofundadas e ilustrativas, sejam elas pequenas ou grandes, o que importa é que sejam capazes de produzir novas informações. (DESLAURIERS, 1991)

Utilizando a pesquisa bibliográfica procurou-se auferir informações que contribuíram para elucidar sobre o cenário da imigração venezuelana, foi feito levantamento de referências teóricas já analisadas, e publicadas por meios escritos e eletrônicos, como livros, artigos científicos que abordam movimentos migratórios em geral, páginas de websites, permitindo conhecer o que já se estudou sobre o assunto, através de referências teóricas publicadas com o objetivo de recolher informações ou conhecimentos prévios sobre o problema a respeito do qual se procura a resposta. (FONSECA, 2002).

Doravante os métodos adotados, buscou-se embasamento científico, bibliográfico, documental, que pudessem levantar hipóteses e soluções para a crise politica, social, econômica e humanitária enfrentada pela Venezuela, como as politicas públicas federais, estaduais e municipais tem se organizado para acolher os imigrantes e como tem ocorrido a interiorização dos interessados nesse processo.

\section{REFLEXOS DA IMIGRAÇAO VENEZUELANA}

Fugindo da insegurança, da escassez de comida e da falta de remédios muitos venezuelanos se arriscam na travessia para o Brasil de ônibus, carona e em muitos casos a pé, uma caminhada que pode levar dias, alguns buscam rotas clandestinas e às vezes precisam pagar propina aos militares da Guarda Nacional Bolivariana, como no caso de quem faz trajeto de Santa Elena de Uairén. Depois de chegar ao Brasil 
ainda fazem um caminho de Pacaraima até Boa Vista de cerca de 215 quilômetros pela BR-174. Os imigrantes fogem com o que podem carregar consigo, documentos, poucas peças de roupas, raros objetos pessoais. Muitos chegam em situação precária, devido as longas caminhadas, famintos e doentes, por interrupção de tratamento e/ou falta de medicamentos. (G1 RR)

Segundo dados do governo federal, até setembro 2018, mais de 65 mil venezuelanos solicitaram refúgio no Brasil e acima de 19 mil solicitaram residência temporária. (ACNUR, 2018)

Com o aumento do fluxo imigratório em Roraima houve uma sobrecarga nos serviços públicos, o estado não estava preparado e não conseguiu sozinho abrigar a demanda de imigrantes que chegam e se concentram por lá, não há condições de inseri todos em programas de moradia, saúde, mercado de trabalho e educação. A área da saúde foi a mais impactada, doenças que já haviam sido eliminadas do território brasileiro voltaram a aparecer, tais como Sarampo. (SOUSA, 2019)

Ao cruzarem a fronteira, além de enfrentar longas filas nos postos de identificação eles ainda precisam enfrentar outra barreira que é a comunicação, nos casos dos não indígenas é um pouco menos complicado, mas há grupos de população indígena que se comunicam através de dialeto próprio, esses são os que mais encontram dificuldades, principalmente os que entram de forma clandestina e já migram para outras regiões. (SIMÕES, 2017)

De acordo com Fernando Souza, representante do Serviço Humanitário SUD (ligado aos Mórmons), no Brasil o que gera a sensação de crise é a falta de politicas públicas que acolham esses imigrantes. No início, houve um apoio da população em receber os imigrantes, mas com o aumento do fluxo a maioria passou a não concordar com essa chegada, resultando em casos de xenofobia, aumentando o preconceito, os conflitos e violência, alargando a situação de vulnerabilidade que a maioria se encontra. Serviços básicos como saúde que já era deficitário para a população local passaram a ser caóticos. Muitos veem os imigrantes como concorrentes por empregos, visto que eles aceitam trabalhar e ganhar menos que os trabalhadores 
locais, (a maioria dos imigrantes não indígenas tem bom nível de escolaridade), ademais os nacionais não gostam do fato dos venezuelanos terem tomado as ruas das cidades, sejam pedindo dinheiro em semáforos ou morando nas ruas. (BRASIL.GOV, 2018)

A Resolução Normativa do Conselho Nacional de Imigração (CNIg) ํo 126, de 02 de março 2017, regulamentou o acordo de residência temporária que permite que estrangeiros possam morar no Brasil por até 2 anos, desde que venha de país fronteiriço e tenha chegado no território brasileiro por meio de via terrestre, bastando apenas apresentar alguns documentos na Policia Federal. Até agosto de 2017, o pedido era pago, mas devido a situação de pobreza que os venezuelanos chegavam ao Brasil, a Justiça Federal de Roraima, através de uma liminar, desonerou a cobrança dessa taxa, passando o processo a ser gratuito. Para entrar em território brasileiro, pela fronteira com a Venezuela, não precisava de visto, os venezuelanos podiam permanecer por até 60 dias como turistas, em virtude da crise no país vizinho o Brasil permitiu o que eles entrassem como refugiados, oferecendo programa de inserção e residência temporária. Todos os solicitantes terão direito a autorização para permanência no Brasil, pois não possui limite no número de vistos permitidos.

Em maio de 2017 foi sancionada a Lei de Migração (Lei no 13.445) que assegura ao migrante condição de igualdade com os nacionais, garantindo direito à vida, à liberdade, à igualdade, à segurança e à propriedade. A lei também permite o visto temporário para acolhida humanitária, a ser concedido aos imigrantes que se fogem de situações de generalizada e grave violação de direitos humanos, condição que possibilita o reconhecimento como refugiado, segundo a Lei $n^{\circ} 9.474$, art. 1으. III. Reflexo da lei, ocorreram investimentos para ampliar a estrutura administrativa, a capacitação e em pessoal, informatizando o sistema de tramitação dos processos referentes ao refúgio, assegurando a celeridade no trâmite processual.

\section{OPERAÇÃO ACOLHIDA[3]}

O Presidente da República, Michel Temer, reconhecendo a vulnerabilidade na condição urgente e emergencial no contexto da proteção social causado pelo fluxo 
migratório causado pela crise humanitária venezuelana, elaborou um conjunto de políticas públicas estruturadas, visando prevenir e impedir situações de risco pessoal e exposição social e que resulte na violação dos direitos humanos dos imigrantes venezuelanos. Publicada no Diário Oficial da União, de 16 de fevereiro de 2018, a Medida Provisória oㅡ 820, de 2018, que decreta medidas de assistência emergencial para acolhimento a pessoas que estejam em situação de vulnerabilidade em consequência do fluxo vindo da República Bolivariana da Venezuela para o Estado de Roraima. Sendo o principal objetivo a inclusão socioeconômica.

Quando passam pela triagem, na Operação Acolhida, vários fatores são levados em consideração, como vontade do imigrante de ficar no país e o desejo em interiorizar para outros estados. Após serem encaminhados para outros estados, os imigrantes ficam em abrigos por tempo determinado, recebem além de serviços básicos, uma carteira de identidade transitória que permite que os venezuelanos possam trabalhar com registro. A MPV 820/2018 possui intersecção com a Lei de Migração (Lei no 13.445, de 2017) e com o Decreto no 9.199, de 20 de novembro de 2017 que a regulamentou.

Tarciso Dal Maso Jardim, Consultor Legislativo, cita sobre a MPV 820/2018, no sumario da medida provisória:

O art. $4^{\circ}$ da medida provisória em tela também arrola que as medidas de assistência emergencial visam à ampliação das políticas de proteção social, atenção à saúde, oferta de atividades educacionais, formação e qualificação profissional, garantia dos direitos humanos, proteção dos direitos das mulheres, crianças, adolescentes, idosos, pessoas com deficiência, população indígena e comunidades tradicionais atingidas, oferta de infraestrutura e saneamento, segurança pública e fortalecimento do controle de fronteiras, logística e distribuição de insumos; e mobilidade, distribuição no território nacional e apoio à interiorização das pessoas em situação de vulnerabilidade, que manifestem previamente essa vontade. (JARDIM, 2018).

De acordo com a MPV 820/2018 os estados e municípios que concordam em receber os migrantes recebem repasse de recursos financeiros do governo federal para terem melhores condições de acomodar o aumento da demanda no Sistema Único de Saúde (SUS) e na educação, sendo serviços de saúde, segurança pública e assistência 
social a prioridade de aplicação dos recursos. Os imigrantes e refugiados são interiorizados após uma avaliação técnica da capacidade de absorção do município, observando condições específicas do migrante, tais como vínculo familiar e a possibilidade de vínculo empregatício. Outras medidas de assistência emergencial incluem além da atenção a saúde e educação, a proteção social, qualificação e formação profissional, garantia e proteção dos direitos de grupos sociais vulneráveis como mulheres, crianças, adolescentes, idosos, população indígena e pessoas com deficiência. Obras de saneamento e infraestrutura, segurança pública, distribuição e logística de insumos e repatriamento também podem ser ampliadas com recursos federais recebidos. Em 21 de junho de 2018, a MPV no 820 foi convertida na Lei № 13.684 .

O Plano de Interiorização visa a integração social e econômica dos imigrantes e refugiados na sociedade de forma adequada e segura. Proporcionando acesso a benefícios assistenciais e oportunidades de emprego e moradia, de forma a ajudar na obtenção da autonomia financeira e possam ter condições dignas para viverem. Os que têm interesse em interiorizar são acompanhados até a cidade de destino, normalmente em voos da Força Aérea Brasileira (FAB).

A interiorização é apoiada por diferentes órgãos, como a Casa Civil da Presidência da República, os Ministérios da Cidadania, da Defesa e da Saúde, os Estados da Federação, prefeituras e organizações não governamentais. Estão ligadas diretamente a Agência da ONU para Refugiados (ACNUR), a Organização Internacional para as Migrações (OIM), o Programa das Nações Unidas para o Desenvolvimento (PNUD), o Fundo de População das Nações Unidas (UNFPA) todas do Sistema ONU. Através dessas organizações são identificados locais de acolhida no País e são as responsáveis por fornecer orientações sobre as cidades de acolhida e realizar as melhorias estruturais nos abrigos.

Em Roraima os abrigos são apoiados ainda pela Associação Voluntários para o Serviço Internacional (AVSI) e da Agência Adventista de Desenvolvimento e Recursos Assistenciais (ADRA), organizações parceiras do ACNUR. Ao chegarem nos abrigos, os imigrantes e refugiados são registrados, documentados e vacinados, recebem três 
refeições diárias fornecidas pelas Forças Armadas e são distribuídos kits de higiene pessoal e de limpeza, que incluem pasta e escova de dente, sabonetes, shampoo e repelente de insetos, absorventes, sabão em pó, detergente, esponjas e desinfetante, além de colchões e papel higiênico e para as famílias que tem bebês também recebem fraldas. Estes itens que não são alimentares são fornecidos pelo ACNUR, pela AVSI, e pela ADRA com recursos de seus doadores. As Forças Armadas são responsáveis por fornecer vacinas, alimentação, transporte, atendimento médico e segurança e também pela infraestrutura física dos abrigos.

\section{CONCLUSÃO}

O presente artigo científico teve como base somente programas desenvolvidos pelo governo visando melhorias para imigrantes venezuelanos, há órgãos não governamentais, igrejas e associações religiosas ou não, que também desenvolvem projetos de melhoria para os imigrantes, mas não existe um estudo oficial e atual sobre os números de atendimentos por parte desses órgãos e também há os imigrantes clandestinos, que não foram atendidos por nenhum desses órgãos e/ou associações e que migraram por conta para outros estados do Brasil em busca de novas oportunidades.

Mesmo com o apoio de organizações não governamentais, a criação de leis e medida provisória, ainda, há muito a fazer para ajudar a situação dos imigrantes, principalmente dos clandestinos que estão nas ruas. Uma saída é uma articulação entre as instituições da Administração Pública com o Comitê Nacional para os Refugiados (CONARE) e o Conselho Nacional de Imigração (CNIg) e a participação das organizações da sociedade civil estabelecer parcerias entre o Ministério da Justiça e Segurança Pública e outras instituições. O setor privado pode auxiliar em parceria com governo brasileiro, participando do mapeamento de oportunidades de emprego que são ofertados aos imigrantes de acordo com as habilidades e competências dos mesmos.

A redução da tensão social e de conflitos necessários também é uma responsabilidade do governo, implementar de forma eficiente, uma estratégia de 
informação e formação de opinião para esclarecer e sensibilizar a opinião pública, estimulando a tolerância e a solidariedade com quem já está sofrendo com a vida fora de seu país. O incentivo a inciativas que apoiem os refugiados e imigrantes na geração de renda de ser igualmente estimulado.

Precisa-se ir além da construção de abrigos, o apoio a rede pública de saúde que está sobrecarregada é primordial e prover assistência as escolas que não estão preparadas para atender a demanda crescente dos imigrantes.

Quanto a estratégia de interiorização, a médio prazo, pode se tornar um grande problema para as cidades, pois se o imigrante não conseguir condições e auto sustento não terá autonomia para se manter em condições dignas, passando a viver como os clandestinos que acabam por morar nas ruas.

Outro fato de suma importância é que não haja deportação ou expulsão dos imigrantes e refugiados que estão à procura de uma vida melhor, um retorno forçado pode agravar a situação dramática que eles já se encontram.

Acima de tudo, qualquer estratégia de politicas públicas deve estar imune a influencias politicas eleitorais e partidárias, pois isso pode expor a novas privações esses que já passam por muitas dificuldades.

\section{REFERÊNCIAS}

ACNUR. Alto Comissariado das Nações Unidas para os Refugiados, 2019. Disponível em: <https://www.acnur.org/portugues/?s=VENEZUELA> Acesso em: 25 fev. 2019.

ACNUR. Novo abrigo expande acolhimento de venezuelanos em Boa Vista. Disponível em: <https://www.acnur.org/portugues/2018/10/23/novo-abrigo-expandeacolhimento-de-venezuelanos-em-boa-vista/> Acesso em: 24 jun. 2019. 
BBC. Crise na Venezuela: 8 perguntas para entender a escalada da tensão no país. Disponível em: <https://www.bbc.com/portuguese/internacional-48113783> de 30/04/2019. Acesso em: 25 jun. 2019.

BRASIL. Constituição (1988). Constituição da República Federativa do Brasil de 1988. Brasília: Presidência da República. Subchefia para Assuntos Jurídicos. Disponível em: <http://www.planalto.gov.br/ccivil_03/constituicao/constituicao.htm>. Acesso em: 11 jun. 2019.

BRASIL. Lei № 13.684, de 21 de junho de 2018.. Diário Oficial [da] República Federativa do Brasil, Poder Executivo, Brasília, DF, 22 jun. 2018.

BRASIL. Lei no 9.474, de 22 de julho de 1997. Define mecanismos para a implementação do Estatuto dos Refugiados de 1951, e determina outras providências. Disponível em: <http://www.planalto.gov.br/ccivil_03/Leis/L9474.htm>. Acesso em: 15 jun. 2019.

BRASIL. Medida provisória no 820, de 15 de fevereiro de 2018. Diário Oficial [da] República Federativa do Brasil, Poder Executivo, Brasília, DF, 18 fev. 2018.

BRASILEIRO, Exercito. Operação Acolhida. Disponível em: $<w w w . e b . m i l . b r / o p e r a c a o-a c o l h i d a>$ Acesso em: 01 jun. 2019.

CANINEU, Maria Laura. Venezuela: Crise Humanitária Alastra-se para o Brasil, 2017.

CIDADANIA, Ministério da. Interiorização de venezuelanos promovida pelo Ministério da Cidadania completa um ano. Disponível em: <http://mds.gov.br/areade-imprensa/noticias/2019/abril/interiorizacao-de-venezuelanos-promovida-peloministerio-da-cidadania-completa-um-ano> Acesso em: 13 jun. 2019.

Council on Foreign Relations. Venezuela: a ascensão e queda de um petrostato. Disponível em: <https://www.cfr.org/backgrounder/venezuela-crisis> Acesso em: 25 jun. 2019. 
DEFESANET. Operação Acolhida: interiorização de venezuelanos ultrapassa marca de $\mathbf{4 . 7 0 0}$ pessoas beneficiadas. Disponível em: $<$ http://www.defesanet.com.br/aciso/noticia/32102/Operacao-Acolhida-interiorizacao-de-venezuelanos-ultrapassa-marca-de-4-700-pessoas-beneficiadas-/> Acesso em: 13 jun. 2019.

FONSECA, J. J. S. Metodologia da pesquisa científica. Fortaleza: UEC, 2002. Apostila.

G1 RR. General de missão humanitária diz que e dificil achar cidades para transferir venezuelanos de RR. Disponível em: <https://g1.globo.com/rr/roraima/noticia/2019/05/31/general-de-missao-humanitariadiz-que-e-dificil-achar-cidades-para-transferir-venezuelanos-de-rr.ghtml> Acesso em: 13 jun. 2019.

G1. Número de refugiados da Venezuela chega a 4 milhões de acordo com a ONU. Disponível em: <https://g1.globo.com/mundo/noticia/2019/06/07/numero-derefugiados-da-venezuela-chega-a-4-milhoes-de-acordo-com-a-onu.ghtml> Acesso em: 13 jun. 2019.

G1. ONU diz que mais de 40 pessoas morreram e 850 foram presas na Venezuela. Disponível em: <https://g1.globo.com/mundo/noticia/2019/01/29/onu-diz-que-40pessoas-morreram-e-850-foram-presas-e-na-venezuela.ghtml> Acesso em: 16 jun. 2019

Gabriela Ruic, de EXAME. 5 pontos para entender a crise na Venezuela. Disponível em: <https://exame.abril.com.br/mundo/5-pontos-para-entender-a-crisena-venezuela/> Acesso em: 19 mai. 2019.

GIL, A. C. Como elaborar projetos de pesquisa. 4. ed. São Paulo: Atlas, 2007.

IOM, Glossário Sobre Migração-no 22 Genebra, 2009. Disponível em: <http://publications.iom.int/system/files/pdf/iml22.pdf>. Acesso em: 03 mar. 2019. 
JARDIM, Tarciso Dal Maso. Sumário Executivo da Medida Provisória. Disponível em: $<$ https://www.congressonacional.leg.br/materias/medidas-provisorias/-/mpv/132234> 19/02/2018 Acesso em: 24 jun. 2019.

MINAS GERAIS, Assembleia de. Proteção a Imigrantes e Refugiados. Disponível em: $<$ https://politicaspublicas.almg.gov.br/temas/protecao_imigrantes_refugiados/entend a/informacoes_gerais.html?tagNivel1=236\&tagAtual=10311> Acesso em: 12 jun. 2019.

OIM. Relatório dos Movimentos assistidos pela OIM. Disponível em: $<$ http://www.casacivil.gov.br/operacao-acolhida/documentos/interiorizacao-relatoriocumulativo-22novembro2018.pdf> Acesso em: 13 jun. 2019.

REPUBLICA, Presidência. Operação Acolhida. Casa Civil. Disponível em: <www.casacivil.gov.br/operacao-acolhida> Acesso em: 01 jun. 2019

RODRIGUES, Francilene. Migração transfronteiriça na Venezuela. In: Estudos Avançados. V. 20, n. 57, 2006, p. 197-207. Disponível em: $<$ https://www.revistas.usp.br/eav/issue/view/746>. Acesso em 10 jun. 2019.

SAMPAIO, Cyntia; SILVA, João Carlos Jarochinski_o Brasil precisa de um plano para os venezuelanos que chegam. Disponível em: <https://brasil.elpais.com/brasi//2018/04/10/opinion/1523393064_479158.html> Acesso em: 11 abr. 2019.

SENADO. Senado aprova apoio emergencial a imigrantes. Disponível em: $<$ https://www12.senado.leg.br/noticias/materias/2018/06/12/senado-aprova-apoioemergencial-a-imigrantes> Acesso em: 25 jun. 2019.

SIMÕES, Gustavo da F.; SILVA, Leonardo C. da; OLIVEIRA, Antônio T. R. de. Á guisa de introdução: imigração venezuelana no Brasil. In: In: SIMÕES, Gustavo da F. (org.). Perfil sociodemográfico e laboral da imigração venezuelana no Brasil. Curitiba: CRV, 2017. 
SOUSA, Rafaela. Imigração venezuelana para o Brasil; Brasil Escola. Disponível em: <https://brasilescola.uol.com.br/brasil/imigracao-venezuelana-para-brasil.htm>. Acesso em: 11 jun. 2019.

TOLEDO, Marcelo; KNAPP, Eduardo. Invasão de venezuelanos fugindo de crise no país gera caos em Roraima Mundo - Folha de Paulo, 2016. <https://www1.folha.uol.com.br/mundo/2016/11/1833815-invasao-de-venezuelanosfugindo-de-crise-no-pais-gera-caos-em-roraima.shtml> Acesso em: 20 jun. 2019

UNIDAS, Nações. Programa de interiorização beneficia mais de 5 mil venezuelanos no Brasil. Disponível em: <https://nacoesunidas.org/programa-de-interiorizacaobeneficia-mais-de-5-mil-venezuelanos-no-brasil/> Acesso em: 13 jun. 2019.

\section{APÊNDICE - REFERÊNCIA DE NOTA DE RODAPÉ}

3. Dados obtidos das páginas oficias da Operação Acolhida. www.eb.mil.br/operacaoacolhida; www.casacivil.gov.br/operacao-acolhida

Enviado: Setembro, 2020.

Aprovado: Outubro, 2020. 